\title{
Effect and molecular mechanism of mTOR inhibitor rapamycin on temozolomide-induced autophagic death of U251 glioma cells
}

\author{
BING LI* ${ }^{*}$ CHUN ZHOU* , LIANG YI, LUNSHAN XU and MINHUI XU \\ Department of Neurosurgery, Daping Hospital, Third Military Medical University, Yuzhong, Chongqing 400042, P.R. China
}

Received September 20, 2015; Accepted November 8, 2016

DOI: $10.3892 / \mathrm{ol} .2017 .7537$

\begin{abstract}
Glioma is a malignant tumor of the glial tissue that is difficult to excise through surgery, with poor patient prognosis. The use of chemotherapeutic drugs alone to treat glioma following surgery results in a high probability of sequelae, such as tumor recurrence. The present study investigated the effects of a novel treatment combination on glioma cells and determined the molecular mechanisms underlying its action. The effect of temozolomide (TMZ) combined with rapamycin (RAPA) on the TMZ-induced autophagic death of U251 glioma cells was examined. The U251 cell line was treated with TMZ combined with RAPA, and the cell survival rate and half maximal inhibitory concentration $\left(\mathrm{IC}_{50}\right)$ of TMZ/RAPA was detected using the Cell Counting Kit-8 (CCK-8) assay. Flow cytometry was used to detect changes in cell cycle distribution. The formation of acidic vesicular organelles (AVOs) in the cytoplasm was identified using fluorescence microscopy and quantitatively analyzed. Western blotting was performed to detect the expression levels of autophagy-associated proteins Beclin-1 and microtubule associated protein 1 light chain 3 alpha (MAP1LC3A)-I and II. RAPA (1.25 nM) combined with $5 \mu \mathrm{M}$ TMZ markedly inhibited U251 cell growth. RAPA reinforced TMZ-induced autophagic death, reducing the $\mathrm{IC}_{50}$ value of treatment when combined (TMZ alone, $22.5 \pm 3.23 \mu \mathrm{M}$ vs. TMZ and RAPA, $10.35 \pm 2.81 \mu \mathrm{M})$. Compared with the control group, the proportion of cells in $\mathrm{G}_{2} / \mathrm{M}$ were markedly increased following treatment with TMZ combined with RAPA. Acridine orange staining demonstrated that TMZ combined with RAPA could markedly enhance the generation of intracellular AVOs compared with TMZ or RAPA alone. In
\end{abstract}

Correspondence to: Dr Minhui Xu or Dr Lunshan Xu, Department of Neurosurgery, Daping Hospital, Third Military Medical University, 10 Changjiangzhilu, Yuzhong, Chongqing 400042, P.R. China

E-mail: minhuixu66@aliyun.com

E-mail: xuliu559@163.com

${ }^{*}$ Contributed equally

Key words: mammalian target of rapamycin, rapamycin, temozolomide, autophagy, glioma addition, Beclin-1 and LC3-II protein expression was markedly increased compared with the control and single treatment groups $(\mathrm{P}<0.05)$. The results of the present study indicate that RAPA reinforces TMZ-induced autophagic death of U251 glioma cells, providing a novel therapeutic combination for the treatment of malignant glioma.

\section{Introduction}

Glioma has one of the highest incidence rates of all malignant tumor types and is the most difficult primary cerebral tumor to treat (1). Cerebral malignant glioma, also named high-grade glioma (HGG) (2), is the most common type of primary intracranial malignant tumor and originates in cranial nerve glial cells (3). The relapse rate of HGG is high and results in the generation of metastases; thus, the median survival time of patients with HGG is only 13 months (4). The typical biological characteristic of this type of malignant tumor is invasive growth, including that into the surrounding healthy brain tissue. Due to the location of such tumors within the brain, it is difficult to remove them using surgery alone, resulting in poor prognosis $(5,6)$. Therefore, the conventional treatment for glioma involves a combination of surgery and chemotherapy. However, patients receiving chemotherapy alone following surgery frequently relapse. Further studies are required in order to develop novel and effective treatments for patients with glioma.

Temozolomide (TMZ) is a small lipophilic molecule that can efficiently pass through the blood-brain barrier (7). TMZ is an alkylating agent that can induce base mismatch and DNA abruption, thus inhibiting tumor cell growth and inducing cell death. Therefore, TMZ is regarded as an important chemotherapeutic drug for the treatment of glioma (8). However, Kalkan et al (9) identified that the expression of multidrug resistance-associated proteins, such as P-glycoprotein and O6-methylguanine-DNA methyl transferase (MGMT), was upregulated in malignant glioma cells following chemotherapy, which induced resistance to chemotherapeutic drugs, such as TMZ. In addition, this study identified an association between the expression of these proteins and the relapse rate of malignant glioma.

There may be other mechanisms of drug resistance in malignant glioma. Zhang et al (10) identified that the median survival time of malignant glioma only increased from 14.6 to 21.7 months following MGMT promoter methylation, which 
resulted in the down regulation of MGMT. Previous studies have demonstrated that TMZ induces and molecularly regulates the autophagy of glioma cells (11). Based on these results, it has been speculated that TMZ resistance could be associated with autophagy. Therefore, in the present study, the combined effect of TMZ and a specific inhibitor of autophagy was investigated in order to elucidate the molecular mechanisms underlying autophagy in cerebral malignant glioma.

Rapamycin (RAPA) is a macrolide antibiotic, which was first widely used as an immunosuppressant, due to its significant effects on multiple autoimmune diseases. In addition, RAPA is used to prevent rejection following organ transplantation, with few side effects. In previous studies, RAPA demonstrated antitumor activity, in addition to specific autophagy inhibition (12-14). The present study aimed to investigate the combined biological effect of TMZ and RAPA on the proliferation, survival, apoptosis, cell cycle distribution and autophagy of cerebral glioma cells, and the underlying molecular mechanisms involved, in order to develop more effective treatments for patients with glioma.

\section{Materials and methods}

Reagents and apparatus. Dulbecco's modified Eagle's medium (DMEM) and fetal bovine serum (FBS) were purchased from Gibco (Thermo Fisher Scientific, Inc., Waltham, MA, USA). Trypsin $(0.25 \%)$ was purchased from Hangzhou Evergreen (Hangzhou, China). Penicillin and streptomycin were purchased from Wuhan Boster Biological Technology, Ltd. (Wuhan, China). RAPA was purchased from the Beyotime Institute of Biotechnology (Haimen, China). TMZ and acridine orange (AO) were purchased from Sigma-Aldrich (Merck KGaA, Darmstadt, Germany).

Cell culture. The human glioma cell line U251, purchased from the Shanghai Institute of the Chinese Academy of Sciences (Shanghai, China), was cultured in DMEM containing $100 \mathrm{U} / \mathrm{ml}$ penicillin and $100 \mu \mathrm{g} / \mathrm{ml}$ streptomycin, supplemented with $10 \% \mathrm{FBS}$ and incubated at $37^{\circ} \mathrm{C}$ with $5 \%$ $\mathrm{CO}_{2}$ in a humidified atmosphere. Medium was changed every 1-2 days. When the cells covered $90 \%$ of the culture flask, they were digested with trypsin and passaged.

Detection of U251 cell survival rate using the cell counting kit-8 (CCK-8) assay. Glioma cells in the logarithmic phase of growth were washed with PBS three times and then digested using $0.25 \%$ trypsin. DMEM containing $10 \%$ FBS was used to achieve a solution of $\sim 1 \times 10^{5}$ cells $/ \mathrm{ml}$. The resulting suspension was added to a $96-$ well plate $(100 \mu \mathrm{l} /$ well $)$. The plate was incubated at $37^{\circ} \mathrm{C}$ with $5 \% \mathrm{CO}_{2}$ for $24 \mathrm{~h}$. The cells were subsequently divided into the control groups (solvent and blank) and the experimental groups (TMZ alone, RAPA alone, and TMZ and RAPA). Different concentrations of TMZ (1-50 $\mu \mathrm{M})$ and/or RAPA (0.625-20 nM) were added to the experimental groups.

Dimethyl sulfoxide $(1 \mu \mathrm{g} / \mathrm{ml})$ was added to the solvent control group and DMEM was added to the blank control group. There were six wells per treatment. Forty-eight hour following the addition of TMZ/RAPA, $10 \mu \mathrm{l} \mathrm{CCK-8} \mathrm{reagent}$ (Sigma-Aldrich; Merck KGaA) was added to each well prior to incubating the plate for a further 2-4 h. An enzyme-linked spectrophotometer was used to detect cell proliferation via measuring the absorbance at $450 \mathrm{~nm}$. The following formula was used to calculate cell viability: $(D-B / C-B) \times 100 \%(D$, absorbance of drug well at $450 \mathrm{~nm} ; B$, absorbance of blank control well at $450 \mathrm{~nm}$; $C$, absorbance of control well at $450 \mathrm{~nm})$.

Detection of cell apoptosis using flow cytometry. A total of $48 \mathrm{~h}$ following treatment with drugs as described above, cells $\left(\sim 5 \times 10^{6}\right.$ cells $\left./ \mathrm{ml}\right)$ were collected $)$ by centrifugation at $200 \mathrm{x} \mathrm{g}$ for $5 \mathrm{~min}$ in room temperature. Cells were subsequently washed in ice-cold PBS and centrifuged again. Cells were resuspended in $100 \mu \mathrm{l} 5 \mathrm{X}$ annexin binding buffer for flow cytometry (Thermo Fisher Scientific Inc.). An additional $5 \mu \mathrm{l}$ APC annexin V and $5 \mu \mathrm{l}$ propidium iodide (PI) (both $100 \mu \mathrm{g} / \mathrm{ml}$ ) were added to the suspension and incubated at room temperature for $15 \mathrm{~min}$. PI fluorescence excitation was performed using an argon ion laser at a wavelength of $488 \mathrm{~nm}$. Annexin V staining was detected using flow cytometry, as aforementioned. Flow cytometry (Attune NxT Flow Cytometer Software, version 2.1, Thermo Fisher Scientific Inc.) was used to detect the effect of the drugs on U251 cell apoptosis.

Detection of cell cycle progression using flow cytometry. A total of $48 \mathrm{~h}$ following treatment with drugs as described above, the cell culture medium was collected into a streaming dedicated pipe. Cells were washed once with $1 \mathrm{ml}$ PBS and cleaning fluid was added to the pipe. The cells were collected into the pipe following digestion with trypsin. The remaining cells were washed with $1 \mathrm{ml}$ PBS and collected $\left(\sim 2 \times 10^{6}\right.$ cells $\left./ \mathrm{ml}\right)$ through centrifugation at $200 \times \mathrm{g}$ for $5 \mathrm{~min}$ in room temperature. This step was repeated to wash the cells. Subsequently, $300 \mu \mathrm{l}$ PBS was used to resuspend the cells and the cells were fixed with $700 \mu$ l of ice-cold $70 \%$ absolute ethanol, which was added dropwise. The cells were immobilized at $-20^{\circ} \mathrm{C}$ for $\geq 24 \mathrm{~h}$ without light. The resultant mixture was centrifuged as described above to remove any stationary liquid. PBS $(500 \mu 1)$ was used to resuspend the cells prior to centrifugation as described above. PI $(5 \mu \mathrm{l})$ was used for staining at $4^{\circ} \mathrm{C}$ for $30 \mathrm{~min}$ without light. Annexin V staining was detected using flow cytometry, as aforementioned.

Immunofluorescence detection. U251 cells were seeded into a 24-well plate with sterile cover slips in place. The culture medium was discarded when all cells had adhered. Cells were washed three times with PBS and paraformaldehyde (4\%) was applied at room temperature for $20 \mathrm{~min}$ to immobilize cells. Cells growing on glass coverslips were permeabilized with Triton X-100 solution ( $0.3 \%$ ) for $15 \mathrm{~min}$. The cells were washed three times with PBS (5 min/wash). Normal goat serum (10\%; Thermo Fisher Scientific Inc.) was used to block non-specific binding and the cells were subsequently incubated at $37^{\circ} \mathrm{C}$ for $60 \mathrm{~min}$.

Cells were incubated with the primary antibody (1:100, CD81 Monoclonal Antibody (1D6), cat. no. MA1-80820, Thermo Fisher Scientific Inc.). Coverslips were then incubated at $4^{\circ} \mathrm{C}$ overnight. The cells were subsequently placed at room temperature for $30 \mathrm{~min}$ and rinsed three times with $0.01 \mathrm{M}$ of PBS (5 min/wash). Secondary antibody [dilution: $10 \mu \mathrm{g} / \mathrm{ml}$, donkey anti-Goat IgG $(\mathrm{H}+\mathrm{L})$ Cross-Adsorbed Secondary 
Antibody, Alexa Fluor 350, catalog no. A-21081, Thermo Fisher Scientific Inc.] was added to the cells cultured on glass coverslips and incubated at $37^{\circ} \mathrm{C}$ for $30 \mathrm{~min}$. Cells were counterstained with DAPI and incubated at $37^{\circ} \mathrm{C}$ for a further $10 \mathrm{~min}$. Cells were washed three times with PBS (5 min/wash) and ProLong anti-fade solution (Thermo Fisher Scientific, Inc.) or glycerinum (Thermo Fisher Scientific Inc.) was used for sealing. Laser scanning confocal microscopy was used for observation and image acquisition.

Detection of acidic vesicular organelles (AVOs) in tumor cells using AO staining. The generation of AVOs is a specific process of autophagy. AO is a fluorochrome that can freely cross the cell membrane. AO accumulates in acidic cell components, generating red fluorescence. This red fluorescence appears when acid phosphatase activity increases during autolysosome formation. The present experiment was performed as described in a previous study, which used the FL1 pathway to detect green fluorescence with an emission maximum at $532 \mathrm{~nm}$ and the FL3 pathway to detect red fluorescence by using 6HFFRPWL Shower Lens, in order to analyze AVO generation in U251 cells (15). U251 cells in the logarithmic phase of growth $\left(1 \times 10^{4}\right.$ cells $\left./ \mathrm{ml}\right)$, were inoculated into a 24 -well plate ( $1 \mathrm{ml} /$ well). Drugs were added the next day as described above and the cells were cultured for a further $72 \mathrm{~h}$. AO $(1 \mu \mathrm{g} / \mathrm{ml})$ was used at $37^{\circ} \mathrm{C}$ to stain the cells for $15 \mathrm{~min}$. The distribution of AVOs was subsequently observed under a fluorescence microscope. Flow cytometry (Attune NxT Flow Cytometer Software, version 2.1, Thermo Fisher Scientific Inc.) was used to quantitatively analyze the rate of AVO generation.

Detection of autophagy marker proteins, apoptosis-associated proteins and protein kinase $B(A k t) /$ mammalian target of rapamycin (mTOR) signaling protein pathway expression using western blotting. After $48 \mathrm{~h}$, cells treated with drugs as described above were collected and left on ice for $30 \mathrm{~min}$, and then sonicated for $10 \mathrm{~min}$ for lysation. The cells were centrifuged at $2,400 \mathrm{x} \mathrm{g}, 12,000 \mathrm{rpm}$ at $4^{\circ} \mathrm{C}$ for $15 \mathrm{~min}$. Protein concentration was detected using the protein assay kit (Quant-iT ${ }^{\mathrm{TM}}$ Protein Assay Kit, Thermo Fisher Scientific Inc.). Loading buffer $(2.5 \mu \mathrm{g} / \mu \mathrm{l}, 20 \mu \mathrm{l})$ was added and the samples were boiled for $5 \mathrm{~min}$ to prepare protein specimens. SDS-PAGE was performed using $20 \mu \mathrm{g}$ protein/lane. Proteins were then transferred to a nitrocellulose membrane. Skimmed milk powder (5\%) was used at room temperature for $1 \mathrm{~h}$ to block the membrane. The membrane was treated with anti-LC3-I (1:1,000; cat. no. PA1-16931), LC3-II (1:1,000; cat. no. PA1-16931), mammalian target of rapamycin (mTOR; 1:1,000; cat. no. PA1-518), phosphorylated (p)-mTOR (1:1,000; cat. no. 25-9718-42), 4E-binding protein 1 (4E-BP1; 1:250; cat no. AHO1382), P70S6K (1:500; cat. no. 710095), p-ribosomal protein S6 kinase (P70S6K; 1:500) and GAPDH (1:1,000; cat. no. MA5-15738) antibodies at $4{ }^{\circ} \mathrm{C}$ overnight. All the above antibodies were purchased from Thermo Fisher Scientific Inc. Horseradish peroxidase-labeled secondary antibody (1:3,000, cat. no. ab6721, Abcam. Cambridge, UK) was applied at room temperature for $1 \mathrm{~h}$. Enhanced chemiluminescence reagent (Pierce ECL Western Blotting Substrate kit, cat. no. 32106, Thermo Fisher Scientific Inc.) was added to analyze specimens using a chemiluminescence imaging system (Alliance MINI
HD9 AUTO Western Blot Imaging system, Biocompare, San Francisco, CA, USA). Western blots were semi-quantified using Quantity One (version 4.6.2; Bio-Rad Laboratories, Inc., Hercules, CA, USA) using three different experimental results.

Statistical analysis. Results are presented as the mean \pm standard deviation. SPSS software (version 13.0; SPSS, Inc., Chicago, IL, USA) was used for statistical analyses. An unpaired t-test was used to compare differences between groups. $\mathrm{P}<0.05$ was considered to indicate a statistically significant difference.

\section{Results}

Effect of TMZ and RAPA on the proliferation and survival of U251 glioma cells. Following treatment with TMZ, U251 cell growth was increased in a dose-dependent manner (Fig. 1A). Growth of the $5 \mu \mathrm{M}$ TMZ-treated group was markedly inhibited by the fourth day $(\mathrm{P}<0.05$, vs. the untreated cells). A total of $48 \mathrm{~h}$ following treatment with TMZ, the half maximal inhibitory rate $\left(\mathrm{IC}_{50}\right)$ of TMZ was calculated. The $\mathrm{IC}_{50}$ of TMZ was $22.5 \pm 3.23 \mathrm{M}$, as illustrated in Fig. 1B. Following treatment with mTOR inhibitor RAPA, the growth of U251 cells was inhibited in a dose-dependent manner (Fig. $1 \mathrm{C}, \mathrm{P}<0.05$, vs. the untreated cells). The $\mathrm{IC}_{50}$ of RAPA was $12.93 \pm 1.36 \mathrm{nM}$, as illustrated in Fig. 1D.

Effect of TMZ combined with RAPA on the survival of U251 glioma cells. The present study demonstrated that the inhibitory rates of $5 \mu \mathrm{M}$ TMZ and $1.25 \mathrm{nM}$ RAPA were 21.36 and $19.23 \%$, respectively (Fig. 2). The inhibitory rate of $50 \mu \mathrm{M}$ TMZ on U251 cell growth was $57.27 \%$, but it showed strong cytotoxicity (data not shown). This is consistent with the results of a previous report (16). In the present study, $5 \mu \mathrm{M}$ TMZ combined with $1.25 \mathrm{nM}$ RAPA was used in order to reduce the cytotoxic effects of TMZ. The results obtained from the CCK- 8 assay demonstrated that the inhibitory effect of TMZ combined with RAPA on cell growth was stronger compared with TMZ alone $(\mathrm{P}<0.05$, in $72 \mathrm{~h})$. The $\mathrm{IC}_{50}$ of TMZ and RAPA combined was notably lower compared with TMZ alone $(10.35 \pm 2.81 \mu \mathrm{M}$ vs. $22.5 \pm 3.23 \mu \mathrm{M}$, respectively; Fig. 2).

Effect of TMZ combined with RAPA on the apoptosis of U251 glioma cells. The high blue: low red apoptotic cells shows no significant difference, which indicates that the apoptosis-inhibiting effect of TMZ combined with RAPA was not notable compared with TMZ alone (Fig. 3).

Effect of TMZ combined with RAPA on the cell cycle distribution of U251 glioma cells. U251 cells were treated with $5 \mu \mathrm{M}$ TMZ and/or 1.25 nM RAPA. Compared with the blank control group, the number of cells in $\mathrm{G}_{1}$ decreased and the number of cells in $\mathrm{G}_{2} / \mathrm{M}$ increased in the groups treated with $5 \mu \mathrm{M}$ TMZ or $1.25 \mathrm{nM}$ RAPA alone. There was no change in S stage cell number (Fig. 4). Following treatment with $5 \mu \mathrm{M}$ TMZ combined with $1.25 \mathrm{nM}$ RAPA, $\mathrm{G}_{2} / \mathrm{M}$ stage cell number was notably higher $(61.07 \pm 2.37)$ compared with the groups treated with TMZ $(31.07 \pm 1.39)$ or RAPA $(27.07 \pm 1.82)$ alone $(\mathrm{P}<0.05$, vs. the other groups; Fig. 4). 
A
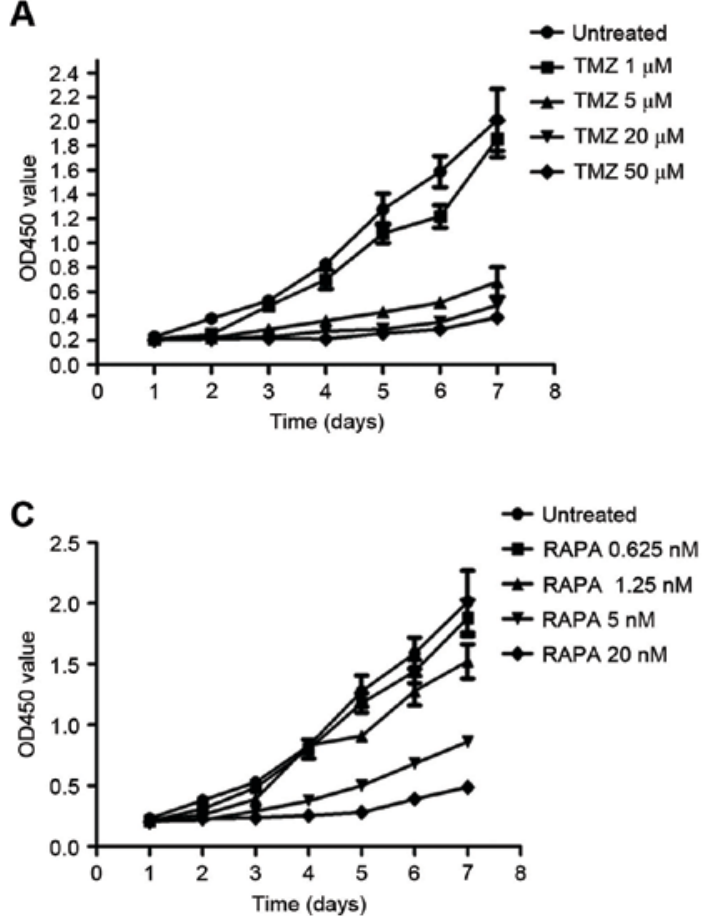

B

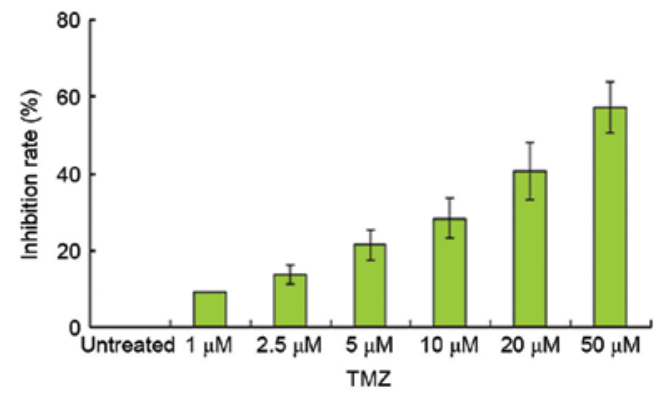

D

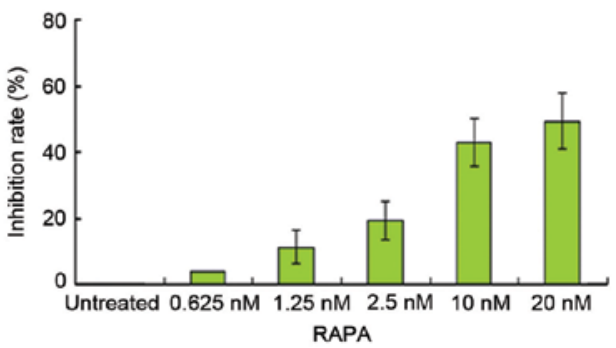

Figure 1. Effect of TMZ and RAPA on the proliferation of U251 cells using the Cell Counting Kit- 8 assay. (A) Effect of TMZ on cell proliferation. (B) IC 50 of TMZ. (C) Effect of RAPA on cell proliferation. (D) $\mathrm{IC}_{50}$ of RAPA. P $<0.05$ vs. the untreated cells; TMZ, temozolomide; RAPA, rapamycin; OD, optical density; $\mathrm{IC}_{50}$, half maximal inhibitory concentration.

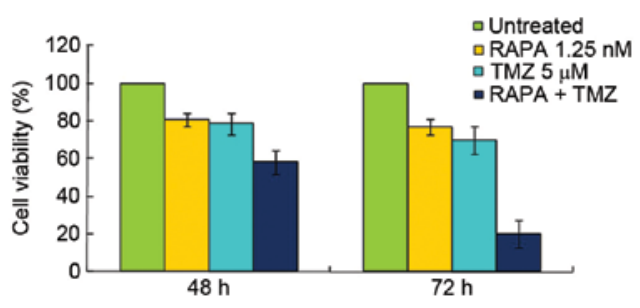

Figure 2. Effect of TMZ combined with RAPA on U251 cell viability using the Cell Counting Kit- 8 assay ( $\mathrm{P}<0.05$ vs. the untreated cells). TMZ, temozolomide; RAPA, rapamycin.
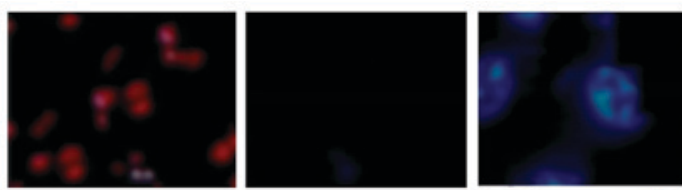

RAPA
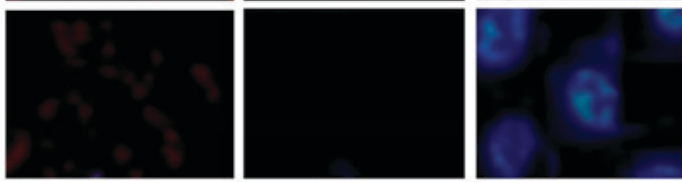

TMZ
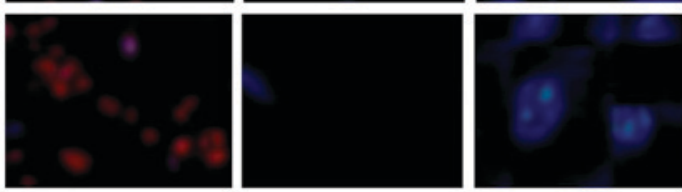

TMZ+RAPA

Figure 3. Effect of TMZ combined with RAPA on U251 cell apoptosis. TMZ, temozolomide; RAPA, rapamycin.

Effect of TMZ combined with RAPA on the autophagy of U25I glioma cells. In the present study, $5 \mu \mathrm{M}$ TMZ combined with

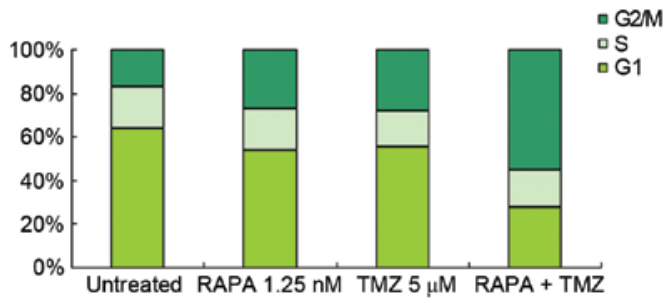

Figure 4. Effect of TMZ combined with RAPA on U251 cell cycle distribution $(\mathrm{P}<0.05 \mathrm{P}<0.05$ vs. the untreated cells). TMZ, temozolomide; RAPA, rapamycin; G, gap phase; M, mitotic phase; $\mathrm{S}$, synthesis phase.

1.25 nMRAPA was used to reduce the cytotoxic effects of TMZ. Following a $24 \mathrm{~h}$ treatment, the expression of autophagy-related protein LC3-II was notably increased compared with the control group $(\mathrm{P}<0.05$; Fig. 5). There was no significant change in LC3-II expression. The Beclin-1 gene is a congener of yeast autophagy-related genes in mammals and an autophagy regulator gene. Expression of Beclin-1 protein was notably increased following treatment with TMZ combined with RAPA $(\mathrm{P}<0.05$; Fig. 5A and D).

Detection of U251 AVO generation by AO staining. AO staining is used to analyze autophagy mechanisms at a molecular level. The results from AO staining (Fig. 6) identified no AVO accumulation in the cytoplasm of the control group. The rate of AVO accumulation was $17.2 \%$ following treatment with $5 \mu \mathrm{M}$ TMZ alone, which was significantly increased compared with the control group $(0.065 \%$; $\mathrm{P}<0.05)$. A similar result was seen following treatment with RAPA alone (AVO accumulation rate, 10.6\%). This indicates that treatment with 
A

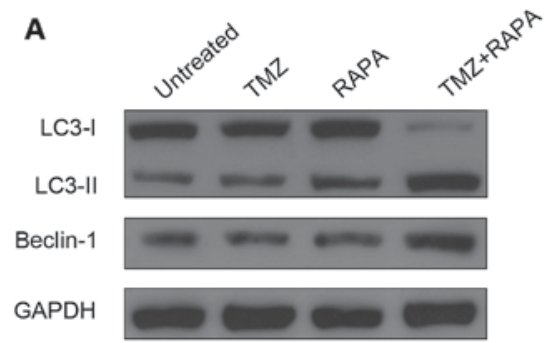

C

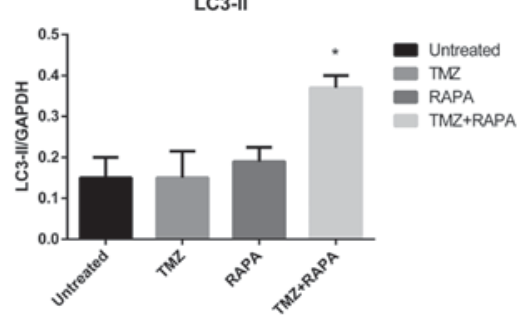

B

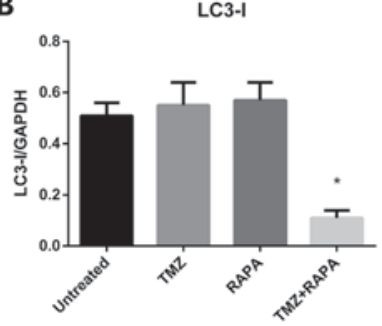

D

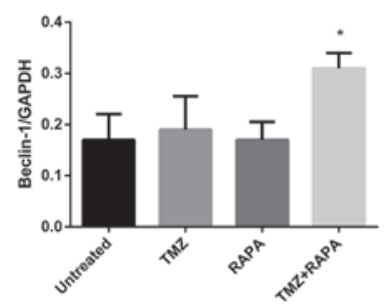

Figure 5. Effect of TMZ combined with RAPA on LC3-I, LC3-II and Beclin-1 protein expression in U251 cells through western blotting analysis. (A) Western blot analysis showing higher LC3-II and Beclin-1 expression in the TMZ+RAPA group than in the other three groups. (B-D) The corresponding statistical analysis results for the western blotting are shown on the right sides of the histograms. The data were obtained from three independent experiments. ${ }^{*} \mathrm{P}<0.05$ vs. the other groups; TMZ, temozolomide; RAPA, rapamycin; MAP1LC3A, microtubule associated protein 1 light chain 3 alpha.

\section{A}

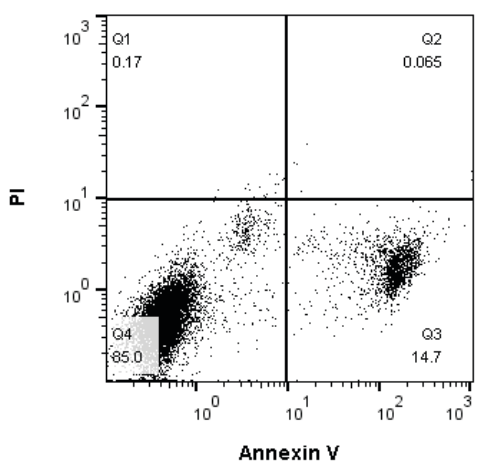

C

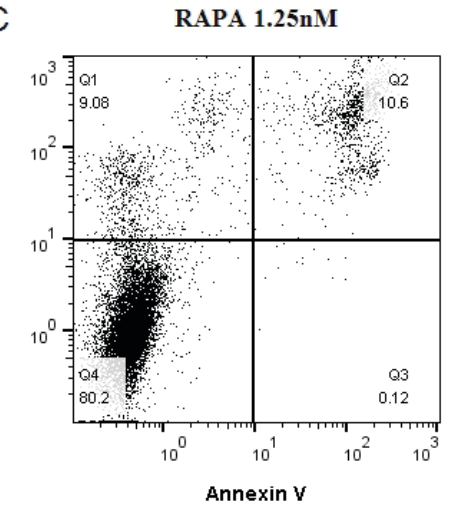

B

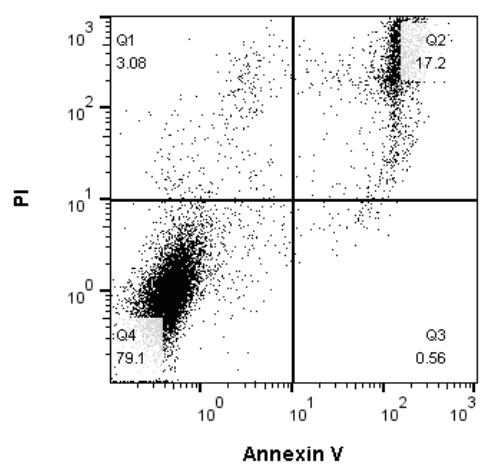

D

\section{TMZ+RAPA}

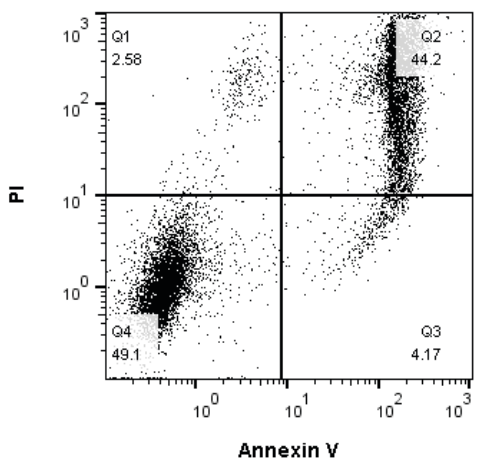

Figure 6. Effect of TMZ combined with RAPA on acidic vesicular organelle generation in U251 cells using acridine orange staining and flow cytometry. (A) Untreated, (B) TMZ-treated, (C) RAPA-treated and (D) TMZ+RAPA-treated cells. TMZ, temozolomide; RAPA, rapamycin; FL, fluorescence.

TMZ or RAPA alone at low concentrations does not effectively induce AVO production in U251 cells. However, the rate of AVO accumulation was notably increased in the cytoplasm of the group treated with TMZ combined with RAPA (44.2\%) compared with the groups treated with TMZ (17.2\%) or RAPA (10.6\%) alone (P<0.05; Fig. 6). 


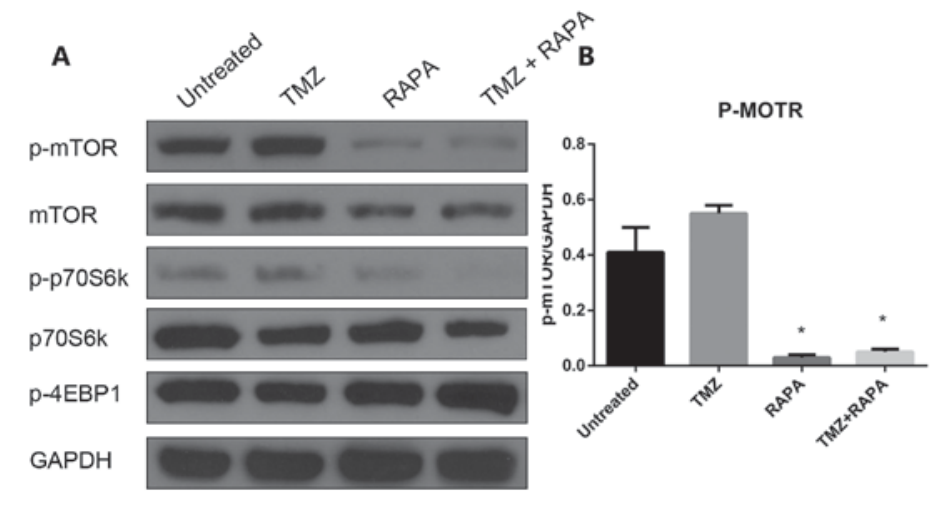

C

D

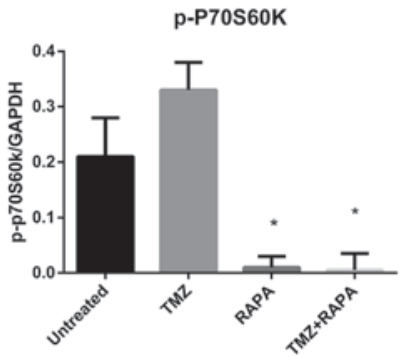

E

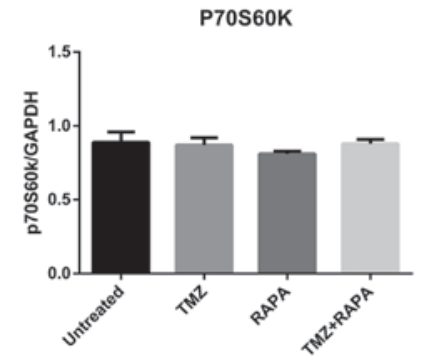

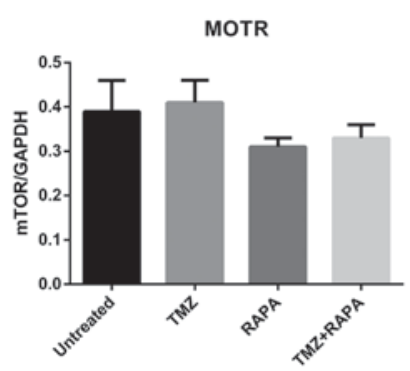

$\mathbf{F}$

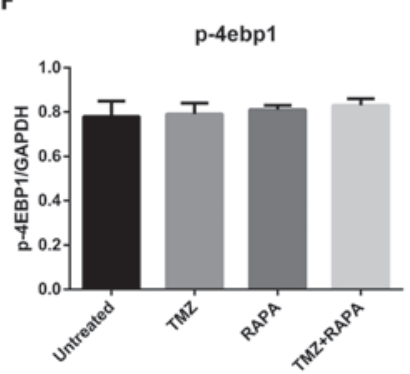

Figure 7. Effect of TMZ combined with RAPA on the expression of autophagy marker proteins, apoptosis-associated proteins and mTOR signaling pathway proteins in U251 cells. (A) Western blot analysis showing significantly lower levels of p-mTOR and p-p70S6k in the RAPA and TMZ+RAPA groups than in the other three groups. (B-F) The corresponding statistical analyses results for the western blotting are shown on the right sides of the histograms. The data were obtained from three independent experiments. "P<0.05 vs. the untreated cells and TMZ group; TMZ, temozolomide; RAPA, rapamycin; p-, phosphorylated; mTOR, mammalian target of rapamycin; P70S6K, ribosomal protein S6 kinase; 4EBP1, eukaryotic translation initiation factor 4E-binding protein 1.

Effect of TMZ combined with RAPA on the autophagy of U251 cells through the mTOR signaling pathway. In order to investigate the molecular mechanisms underlying the induction of autophagy in U251 cells treated with TMZ combined with RAPA, the expression and activation of important components of the mTOR signaling pathway, such as p-mTOR, p-p70S6K and P-4EBP1, was measured following treatment with TMZ alone, RAPA alone or TMZ combined with RAPA. The results demonstrated that the expression of p-mTOR and p-p70S6 significantly decreased in the combination treatment group compared with the groups treated with TMZ or RAPA alone $(\mathrm{P}<0.05$, Fig. 7$)$. A similar trend was seen in the expression of $\mathrm{mTOR}(\mathrm{P}<0.05$, Fig. 7A and $\mathrm{C})$. There was no notable change in the expression of p70S6K and $\mathrm{P}-4 \mathrm{EBP} 1$ in the combination treatment group compared with the single treatment groups $(\mathrm{P}>0.05$, Fig. $7 \mathrm{E}$ and $\mathrm{F})$. These results indicate that TMZ and RAPA-induced autophagy of U251 cells is associated with the mTOR signaling pathway.

\section{Discussion}

The three types of cell death include apoptosis, autophagy and necrosis. The majority of chemotherapeutic drugs induce the apoptosis of tumor cells. Autophagy is a type of programmed cell death (type II). In autophagy, an autophagosome is a monolayer or bilayer membrane that accumulates products to be degraded in the cytoplasm and delivers them to the lysosomes, thus forming autolysosomes. Autolysosomes carry out the digestion and degradation of these products using multiple enzymes, in order to achieve the metabolic needs of the cell and the renewal of specific organelles (17-19). Autophagy serves an important role in maintaining cell homeostasis. In certain tumors, inducing autophagy can significantly inhibit growth and proliferation $(20,21)$. Using AO staining, the present study demonstrated that treatment with TMZ alone induces the generation of AVOs in U251 cells in a dose-dependent manner. The $\mathrm{IC}_{50}$ of $\mathrm{TMZ}$ in $\mathrm{U} 251$ cells was $22.5 \pm 3.23 \mu \mathrm{M}$; however, this concentration is highly toxic and known to induce side effects in patients (20). Low concentrations of RAPA $(\leq 2 \mathrm{nM})$ strengthened TMZ-induced autophagic cell death; thus, the dosage of TMZ was able to be decreased (20). The combined use of RAPA and TMZ increased the generation of AVOs in U251 glioma cells. As the primary indicator of autophagic cell death is the generation of AVOs, these results indicate that the combination of these two drugs may be used to synergistically inhibit glioma cell growth.

The induction of autophagy has been associated with a series of evolutionarily conserved gene products that were first discovered in yeast and named autophagy-related gene (Atg) proteins. In mammals, LC3-I is an autophagic vacuolar protein that is isogenous with Atg 8 (22). During cell autophagy, LC3-I is cleaved to produce LC3-II, which serves an important role in AVO generation and is regarded as a molecular marker of autophagic cell death $(23,24)$. TMZ induces autophagy in other ways (25). Zou et al (26) identified that TMZ inhibited the growth of glioma cells and decreased the number of cells in $S$ and $G_{2} / M$, leading to atypical cell apoptosis. The present study identified that the use of TMZ alone to treat U251 cells induces a slight increase in autophagy-related proteins and may induce the apoptosis of glioma cells to a certain extent, which is consistent with a previous study (15). 
mTOR is a central regulator of cell growth, proliferation, survival, migration, self-renewal and cell cycle progression (27-29). The downstream effectors of mTOR include eukaryotic translation initiation factor 4E-binding protein 1 and P70S6K. These two downstream effectors control expression of cyclin D1 and cyclin-dependent kinase in eukaryotes (30-32). Thoury et al (33) combined RAPA derivative RAD001 with AEE788 (an epidermal growth factor receptor/vascular endothelial growth factor receptor double tyrosine kinase inhibitor) to treat D54MG glioma in a murine model. This combination was demonstrated to significantly inhibit tumor cell growth and proliferation, and the median survival time of the mice was significantly longer in the combined treatment group compared with the groups treated with AEE788 or RAD001 alone. Wang et al (34) demonstrated that combining RAPA with an inhibitor of the mTOR upstream regulator molecules phosphoinositide 3-kinase and Akt significantly sensitized cells to RAPA-mediated autophagy and resulted in radiosensitization.

The present study demonstrated that autophagy-associated protein concentrations in U251 cells markedly increased following treatment with TMZ combined with RAPA. Furthermore, the number of $\mathrm{G}_{2} / \mathrm{M}$ stage cells significantly increased in the combined treatment group compared with the single treatment groups. AO staining identified that the amount of AVOs increased in cells treated with TMZ combined with RAPA, indicating that the combination promotes autophagic cell death. These results suggest that RAPA may be combined with other drugs or therapies to effectively inhibit the growth and proliferation of glioma cells.

The results of the current study demonstrated that RAPA combined with TMZ induces the expression of Beclin-1 and LC3-II in U251 cells. These proteins serve important roles in autophagy. Beclin-1 is upregulated by certain autophagy-inducing agents, such as the histone deacetylase inhibitor suberoylanilide hydroxamic acid-d5. The findings of the present study are consistent with those reported by Ye et al (35), in which small interfering RNA knockdown of Beclin-1 expression resulted in the inhibition of autophagic cell death.

To conclude, the results of the present study indicate that a low concentration of RAPA significantly strengthens TMZ-induced autophagic death of U251 cells, thus providing a novel therapeutic approach for the treatment of patients with malignant glioma.

\section{Acknowledgements}

The present study was supported by the National Natural Science Foundation of China (grant nos. 81270039 and 30901538), the Chinese Postdoctoral Science Foundation (grant no. 2013M530388) and the Chongqing Postdoctoral Science Foundation (grant no. Xm201341).

\section{References}

1. Strowd RE III, Holdhoff M and Grossman SA: Chemotherapy for treatment of grade II gliomas. Oncology (Williston Park) 28 1036-1043, 2014.

2. Pedeutour-Braccini Z, Burel-Vandenbos F, Gozé C, Roger C, Bazin A, Costes-Martineau V, Duffau H and Rigau V: Microfoci of malignant progression in diffuse low-grade gliomas: Towards the creation of an intermediate grade in glioma classification? Virchows Arch 466: 433-444, 2015.
3. Chamberlain MC: Glioblastoma in the Elderly. Current Understanding and Treatment of Gliomas: 159-170, 2015.

4. Friedmann-Morvinski D: Glioblastoma heterogeneity and cancer cell plasticity. Crit Rev Oncog 19: 327-336, 2014.

5. Wang X, Zhao HY, Zhang FC, Sun Y, Xiong ZY and Jiang XB: Dendritic cell-based vaccine for the treatment of malignant glioma: A systematic review. Cancer Invest 32: 451-457, 2014.

6. Altieri R, Agnoletti A, Quattrucci F, Garbossa D, Calamo Specchia FM, Bozzaro M, Fornaro R, Mencarani C, Lanotte M, Spaziante R and Ducati A: Molecular biology of gliomas: Present and future challenges. Transl Med UniSa 10: 29-37, 2014.

7. Simonetti G, Gaviani P, Innocenti A, Botturi A, Lamperti E and Silvani A: Update on treatment strategies for anaplastic glioma: A review of literature. Neurol Sci 35: 977-981, 2014.

8. Okita Y, Nonaka M, Umehara T, Kanemura Y, Kodama Y, Mano M and Nakajima S: Efficacy of temozolomide and bevacizumab for the treatment of leptomeningeal dissemination of recurrent glioblastoma: A case report. Oncol Lett 9: 1885-1888, 2015.

9. Kalkan R, Atli Eİ, Özdemir M, Çiftçi E, Aydin HE, Artan S and Arslantaş A: IDH1 mutations is prognostic marker for primary glioblastoma multiforme but MGMT hypermethylation is not prognostic for primary glioblastoma multiforme. Gene 554: 81-86, 2015.

10. Zhang Y, Wang SX, Ma JW, Li HY, Ye JC, Xie SM, Du B and Zhong XY: EGCG inhibits properties of glioma stem-like cells and synergizes with temozolomide through downregulation of P-glycoprotein inhibition. J Neurooncol 121: 41-52, 2015.

11. Turner KM, Sun Y, Ji P, Granberg KJ, Bernard B, Hu L, Cogdell DE, Zhou X, Yli-Harja O and Nykter M: Genomically amplified Akt3 activates DNA repair pathway and promotes glioma progression. Proc Natl Acad Sci USA 112: 3421-3426, 2015.

12. Barber NA and Ganti AK: Pulmonary toxicities from targeted therapies: A review. Target Oncol 6: 235-43, 2011.

13. Kuo PL, Hsu YL and Cho CY: Plumbagin induces G2-M arrest and autophagy by inhibiting the AKT/mammalian target of rapamycin pathway in breast cancer cells. Mol Cancer Ther 5: 3209-3221, 2006.

14. Zangari M, Cavallo F and Tricot G: Farnesyltransferase inhibitors and rapamycin in the treatment of multiple myeloma. Curr Pharm Biotechnol 7: 449-453, 2006.

15. Tang JH, Ma ZX, Huang GH, Xu QF, Xiang Y, Li N, Sidlauskas K, Zhang EE and Lv SQ: Downregulation of HIF-1a sensitizes U251 glioma cells to the temozolomide (TMZ) treatment. Exp Cell Res 343: 148-158, 2016.

16. Kouroussis C, Vamvakas L, Vardakis N, Kotsakis A, Kalykaki A, Kalbakis K, Saridaki Z, Kentepozidis N, Giassas S and Georgoulias V: Continuous administration of daily low-dose temozolomide in pretreated patients with advanced non-small cell lung cancer: A phase II study. Oncology 76: 112-117, 2009.

17. Liu H, Cao Y, Tong T, Shi J,Zhang Y, Yang Y and Liu C: Autophagy in atherosclerosis: A phenomenon found in human carotid atherosclerotic plaques. Chin Med J (Engl) 128: 69-74, 2015.

18. Sheng $\mathrm{R}$ and Qin $\mathrm{ZH}$ : The divergent roles of autophagy in ischemia and preconditioning. Acta Pharmacol Sin 36: 411-420, 2015.

19. Gewirtz DA: Autophagy and senescence in cancer therapy. J Cell Physiol 229: 6-9, 2014.

20. Morselli E, Galluzzi L, Kepp O, Vicencio JM, Criollo A, Maiuri MC and Kroemer G: Anti- and pro-tumor functions of autophagy. Biochim Biophys Acta 1793: 1524-1532, 2009.

21. Kondo Y and Kondo S: Autophagy and cancer therapy. Autophagy 2: 85-90, 2006.

22. Mareninova O, Jail W, Elperin J, Lotshaw E, Pimiental M, Reicher B, Gukovsky I and Gukovskaya A: LC3 overexpression perturbs pancreatic acinar cell homeostasis and alters pancreatitis responses. FASEB J 30 (1 Suppl 920): S12, 2016.

23. Xiong Y, Yepuri G, Forbiteh M, Yu Y, Montani JP, Yang Z and Ming XF: ARG2 impairs endothelial autophagy through regulation of mTOR and PRKAA/AMPK signaling in advanced atherosclerosis. Autophagy 10: 2223-2238, 2014.

24. Luo L, Lu AM, Wang Y, Hong A, Chen Y, Hu J, Li X and Qin ZH: Chronic resistance training activates autophagy and reduces apoptosis of muscle cells by modulating IGF-1 and its receptors, Akt/mTOR and Akt/FOXO3a signaling in aged rats. Exp Gerontol 48: 427-436, 2013.

25. Yang MC, Loh JK, Li YY, Huang WS, Chou CH, Cheng JT, Wang YT, Lieu AS, Howng SL, Hong YR and Chou AK: $\mathrm{Bcl} 2 \mathrm{~L} 12$ with a BH3-like domain in regulating apoptosis and TMZ-induced autophagy: A prospective combination of ABT-737 and TMZ for treating glioma. Int J Oncol 46: 1304-1316, 2015 
26. Zou Y, Wang Q, Li B, Xie B and Wang W: Temozolomide induces autophagy via ATM-AMPK-ULK1 pathways in glioma. Mol Med Rep 10: 411-486, 2014.

27. Zheng DM, Bian Z, Furuya N, Oliva Trejo JA, Takeda-Ezaki M, Takahashi K, Hiraoka Y, Mineki R, Taka $\mathrm{H}$ and Ikeda S: A treadmill exercise reactivates the signaling of the mammalian target of rapamycin (mTOR) in the skeletal muscles of starved mice. Biochem Biophys Res Commun 456: 519-526, 2015.

28. Sarkar S: Regulation of autophagy by mTOR-dependent and mTOR-independent pathways: Autophagy dysfunction in neurodegenerative diseases and therapeutic application of autophagy enhancers. Biochem Soc Trans 41: 1103-1130, 2013.

29. Kubrusly MS, Corrêa-Giannella ML, Bellodi-Privato M, de Sá SV, de Oliveira CP, Soares IC, Wakamatsu A, Alves VA, Giannella-Neto D, Bacchella T, et al: A role for mammalian target of rapamycin (mTOR) pathway in non-alcoholic steatohepatitis related-cirrhosis. Histol Histopathol 25: 1123-1131, 2010.

30. Zhang J, Cao J, Weng Q, Wu R, Yan Y, Jing H, Zhu H, He Q and Yang B: Suppression of hypoxia-inducible factor 10 (HIF-1 $\alpha$ ) by tirapazamine is dependent on eIF $2 \alpha$ phosphorylation rather than the mTORC1/4E-BP1 pathway. PLoS One 5: e13910, 2010.
31. Guan L, Song K, Pysz MA, Curry KJ, Hizli AA, Danielpour D, Black AR and Black JD: Protein kinase C-mediated downregulation of cyclin D1 involves activation of the translational repressor 4E-BP1 via a phosphoinositide 3-kinase/Akt-independent, protein phosphatase $2 \mathrm{~A}$-dependent mechanism in intestinal epithelial cells. J Biol Chem 282: 14213-14225, 2007.

32. Fan QW and Weiss WA: Targeting the RTK-PI3K-mTOR axis in malignant glioma: Overcoming resistance. Curr Top Microbiol Immunol 347: 279-96, 2010.

33. Thoury A, Descatoire V, Kotelevets L, Kannengiesser C, Bertrand G, Theou-Anton N, Frey C, Genestie C, Raymond E, Chastre E, et al: Evidence for different expression profiles for c-Met, EGFR, PTEN and the mTOR pathway in low and high grade endometrial carcinomas in a cohort of consecutive women. Occurrence of PIK3CA and K-Ras mutations and microsatellite instability. Histol Histopathol 29: 1455-1466, 2014.

34. Wang S, Wu M, Yao G, Zhang J and Zhou J: The cytoplasmic tail of FPC antagonizes the full-length protein in the regulation of mTOR pathway. PLoS One 9: e95630, 2014.

35. Ye LX, Yu J, Liang YX, Zeng JS, Huang RX and Liao SJ: Beclin 1 knockdown retards re-endothelialization and exacerbates neointimal formation via a crosstalk between autophagy and apoptosis. Atherosclerosis 237: 146-154, 2014. 